\title{
Morfofisiologia da rebrota de Baccharis trimera (Less) DC., Asteraceae: Subsídios para seu controle em pastagens naturais
}

\author{
Simone Meredith Scheffer-Basso* \\ Ricardo Lubenow \\ Cerci Maria Carneiro \\ Silvia Ortiz Chini \\ Instituto de Ciências Biológicas, Universidade de Passo Fundo, Campus I \\ CEP 99001-970, Passo Fundo, RS, Brasil \\ * Autora para correspondência \\ sbasso@upf.br
}

Submetido em 18/01/2008

Aceito para publicação em 09/06/2008

\section{Resumo}

O trabalho foi conduzido em área de pastagem natural do Rio Grande do Sul, com o objetivo de avaliar a rebrota da carqueja (Baccharis trimera) a cortes em diferentes alturas $(7$ e $15 \mathrm{~cm})$ e estádios fenológicos ( $\mathrm{V}=$ vegetativo; início da primavera; $\mathrm{FF}=$ final do florescimento; final do verão) e determinar histologicamente a natureza do sistema subterrâneo horizontal da espécie. Os cortes foram em 26/09/02 (V) e 14/03/03 (FF) e a avaliação da rebrota foi realizada aos 1.525 graus-dia (V), em 12/12/02, e aos 1.749 graus-dia (FF), em 26/06/03, mediante a colheita da parte aérea. Houve menor produção de matéria seca (MS) nas plantas cortadas no estádio- $\mathrm{V}$, independente da altura de corte (22,9g MS/planta). No corte do estádio-FF houve efeito significativo da altura de corte: a $7 \mathrm{~cm}$ obteve-se $21,7 \mathrm{~g}$ MS/planta e a $15 \mathrm{~cm}, 75,6 \mathrm{~g} \mathrm{MS} /$ planta. Concluiu-se que é melhor cortar a carqueja no estádio vegetativo (primavera) a $15 \mathrm{~cm}$, o que minimizaria os danos às plantas forrageiras desejáveis. A roçada realizada no final do verão, em plantas florescidas, deve ser a menor altura $(7 \mathrm{~cm})$, a fim de reduzir o crescimento das hastes basilares. O sistema subterrâneo horizontal da carqueja é formado por raízes gemíferas, capazes de gerar novas plantas a partir da ativação de gemas dormentes.

Unitermos: alturas de corte, estádios fenológicos, roçadas

\section{Abstract}

Regrowth morphophysiology of Baccharis trimera (Less) DC., Asteraceae): Subsidies for control in natural pastures. This experiment was carried out on native grassland in Rio Grande do Sul. The purpose was to compare the vigor of the regrowth of Baccharis trimera after cutting at different heights $(7$ and $15 \mathrm{~cm})$ and phenological stages ( $\mathrm{V}=$ vegetative; beginning of spring; $\mathrm{FE}=$ end of flowering; end of summer). The design was completely randomized with ten replications, composed by plants. The cuts were on 09/26/02 (V) and $03 / 14 / 03$ (FE); the regrowth evaluation was made after the plants had achieved thermal sums of 1,525 degreedays (12/12/02) and 1,749 degree-days (06/26/03) for V-stage and FE-stage cuts respectively, by harvesting the plant shoots. The lowest regrowth was observed in the plants cut in the V-stage $(22.9 \mathrm{~g} \mathrm{DM} / \mathrm{plant})$, in which the cutting height had no effect. In the FE-stage there was a significant effect of the cutting height: $21.7 \mathrm{~g} \mathrm{DM} /$ plant was obtained under $7 \mathrm{~cm}$ and $75.6 \mathrm{~g} \mathrm{DM} /$ plant was obtained under $15 \mathrm{~cm}$. It was concluded that it is better to cut $B$. trimera in the vegetative stage (beginning of spring) at a height of $15 \mathrm{~cm}$ to minimize possible damage 
to valuable forage plants. Mowing realized at the end of the summer, when the plants are in the flowering stage, needs to be severe $(7 \mathrm{~cm})$ in order to reduce the basal stem growth. The horizontal underground system of $B$. trimera is formed by budding roots, and new shoots can be produced from the activation of their dormant buds.

Key words: cutting height, mowing, phenological stage

\section{Introdução}

A carqueja (Baccharis trimera (Less) DC.) é uma das espécies indesejáveis mais freqüentes nos campos do sul do Brasil. É uma planta perene, grande produtora de sementes e não consumida pelos animais, florescendo desde meados do verão até o final do outono. A falta de controle dessa espécie reduz a área de pastejo e a qualidade da forragem disponível, diminuindo a produtividade das pastagens e, conseqüentemente, a produção animal. A espécie é heliófita e resistente a geadas. Ao nascer apresenta uma série de folhas, que vão regredindo à medida que a planta cresce, até desaparecer totalmente e a fotossíntese é, então, realizada pelos caules alados. Na fase adulta, possui um caule subterrâneo e raiz ramificada (Castro e Ferreira, 2000). Segundo Biasi e De Bona (2000), as raízes da carqueja não penetram profundamente no solo compactado $\mathrm{e}$ crescem acompanhando a superfície do solo.

Nuñez e Del Puerto (1988), no Uruguai, evidenciaram a importância da época de corte ou pastejo no controle dessa espécie, mostrando que os cortes no outono são mais eficazes. Porém, esse efeito não seria em razão da condição morfofisiológica das plantas, mas, sim, um efeito indireto da roçada, uma vez que os novos ramos formados são tenros e consumidos pelos animais numa época de escassez de pasto. Pela experiência de pecuaristas, as roçadas reduzem a freqüência da carqueja nas pastagens naturais. No entanto, essa técnica pode ser mais eficiente se realizada de acordo com critérios morfofisiológicos, pelos quais pode ser observado o vigor da rebrota após os cortes. Normalmente, as pastagens são roçadas no final do inverno e/ou no final do verão, com objetivo de remover o material não pastejado e envelhecido.

No manejo de plantas forrageiras perenes, é comumente afirmado que, para as plantas apresentarem maior persistência e produção ao longo do tempo, os cortes devem ser realizados no estádio reprodutivo, em razão de que nesse período a planta possui maior quantidade de reservas orgânicas nas raízes, coroa e base dos caules (Smith, 1962). Assim, os cortes nesse estádio promoveriam rebrotas mais vigorosas. Por outro lado, cortes intensos, que deixam menor resíduo, por removerem maior área fotossintética e maior número de gemas axilares reduziriam o vigor das plantas. Tais referências poderiam servir de subsídios, também, para as roçadas de limpeza e controle de espécies indesejáveis em pastagens naturais.

Este trabalho foi conduzido com o objetivo de avaliar a rebrota de plantas de carqueja submetidas a cortes em diferentes alturas e distintos estádios fenológicos e analisar, mediante análise anatômica, a natureza do sistema subterrâneo horizontal das plantas.

\section{Material e Métodos}

O trabalho foi conduzido em uma área de pastagem natural, na Fazenda da Brigada Militar, em Passo Fundo, região fisiográfica do Planalto Médio, norte do Rio Grande do Sul, com altitude de $693 \mathrm{~m}$ e clima subtropical úmido (Cfa). As informações quanto às temperaturas e pluviosidade mensais relativas ao período experimental estão apresentadas na figura 1 . O solo da área experimental é do tipo Latossolo Vermelho Escuro Distrófico e apresentou as seguintes características: $\operatorname{argila}=35 \%$; M.O. $=3,2 \% ; \mathrm{pH} \mathrm{H}_{2} \mathrm{O}=4,7 ; \mathrm{P}=3 \mathrm{mg} / \mathrm{L}$; $\mathrm{K}=81 \mathrm{mg} / \mathrm{L} ; \mathrm{Al}=2,2 \mathrm{cmol} \mathrm{c} / \mathrm{L} ; \mathrm{Ca}=2,1 \mathrm{cmol} \mathrm{c} / \mathrm{L}$; $\mathrm{Mg}=1,3 \mathrm{cmol} \mathrm{c} / \mathrm{L} ; \mathrm{CTC}=19,0 ;$ Saturação de Bases = 19\%; Saturação de $\mathrm{Al}=38 \%$. A área onde se conduziu o ensaio tem histórico de pastejo com lotação contínua por bovinos e nunca sofreu práticas de melhoramento. A vegetação rasteira tem predominância de gramaforquilha (Paspalum notatum Flügge) e, no estrato superior, é composta por Baccharis sp. e caraguatás (Eryngium sp.). 


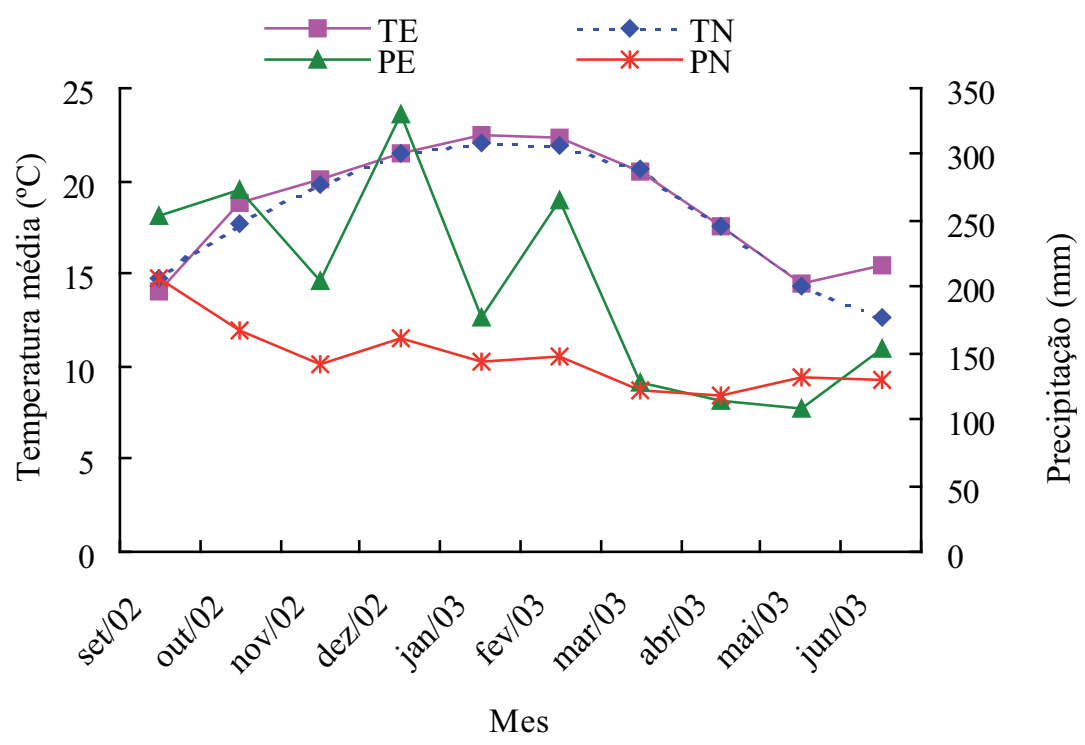

FIGURA 1: Temperatura média $(\mathrm{T})$ e precipitação pluviométrica $(\mathrm{P})$ mensais durante o período experimental (E) e normais regionais $(\mathrm{N})$.

O experimento foi desenvolvido entre setembro/02 e junho/03 e constituiu de um bifatorial, no qual as plantas foram submetidas a cortes em dois estádios fenológicos (vegetativo, início da primavera; final do florescimento; final do verão) e altura de corte $(7 \mathrm{~cm} ; 15 \mathrm{~cm}) . \mathrm{O}$ delineamento foi completamente casualizado, com dez repetições, num total de quarenta unidades experimentais. As unidades experimentais foram compostas por plantas individuais, previamente selecionadas pela sua similaridade quanto à altura, diâmetro e fenologia. As plantas foram sorteadas e marcadas com uma estaca de madeira ao lado da touceira identificando o tratamento correspondente. Os cortes foram realizados com tesoura de poda, no início da primavera, em 26/09/02 (estádio vegetativo) e final de verão, em 14/03/2003 (final de florescimento). As avaliações para a verificação do efeito dos tratamentos foram realizadas em 12/12/2002, para as plantas cortadas no estádio vegetativo e em $26 / 06 / 2003$, para as plantas cortadas no florescimento pleno. $\mathrm{O}$ intervalo entre o corte de imposição dos tratamentos e a avaliação foi determinado pela soma térmica em unidades de graus-dia (GD), de acordo com Romo e Edleman (1995), segundo os quais o uso dessa medida de tempo pode ser mais significativo que unidades cronológicas do calendário humano. Assim, após a colheita das plantas cortadas no estádio vegetativo (1525 GD, aos 77 dias de rebrota), foram somadas semanalmente as temperaturas médias acima de $0^{\circ} \mathrm{C}$ para realizar a colheita das plantas cortadas no florescimento. Em virtude das chuvas, a colheita só foi feita aos 1749 GD (104 dias), num excedente de 224 GD em relação ao estádio vegetativo, que, para as condições de temperatura da época correspondeu a aproximadamente nove dias de atraso. As medidas lineares, de peso e contagem foram, então, divididas pela soma térmica, a fim de verificar se o atraso na avaliação das plantas cortadas no estádio de florescimento teve algum efeito sobre os resultados.

Os cortes foram realizados com tesouras de poda nas alturas pré-determinadas, com exceção do corte de avaliação, que foi rente ao solo. Imediatamente antes dos cortes as plantas foram avaliadas quanto à altura e diâmetro basal. O material coletado foi embalado em sacos plásticos e levado até o laboratório, onde as hastes foram separadas em: hastes mortas, hastes oriundas da coroa e hastes axilares. As hastes foram contadas e posteriormente colocadas em estufa a $60^{\circ} \mathrm{C}$, até peso constante, e, então, pesadas. Os dados referentes 
à condição das plantas no momento dos cortes e os obtidos na colheita final, no total e por grau-dia, foram submetidos à análise de variância, com comparação de médias pelo teste de Tukey a 5\%. Como os resultados foram iguais, optou-se por apresentar a comparação de médias dos dados referentes ao total dos dias de rebrota.

Para a verificação da natureza do sistema subterrâneo horizontal foi realizada a coleta de uma planta inteira. A parte subterrânea foi separada, lavada em água corrente e, segmentos dessa foram fixados em FAA 70 por 48 horas. Posteriormente foram lavadas novamente e transferidas para álcool $70^{\circ} \mathrm{GL}$. A preparação das lâminas foi feita mediante secção a mão livre. As melhores secções foram selecionadas e coradas com fucsina e azul de astra. O meio de montagem utilizado foi glicerina $50 \%$. As análises foram feitas em microscopia de luz e as imagens tomadas mediante câmera digital acoplada ao microscópio.

\section{Resultados e Discussão}

Por ocasião da imposição dos tratamentos, as plantas em final do florescimento estavam significativamente maiores e com maior quantidade de matéria seca (MS), tanto verde, quanto senescente (Tabela 1).

TABELA 1: Condição das plantas de carqueja na época da imposição dos tratamentos de corte.

\begin{tabular}{lcc}
\hline \multirow{2}{*}{ Parâmetros } & \multicolumn{2}{c}{ Estádio fenológico de corte } \\
\cline { 2 - 3 } & $\begin{array}{c}\text { Vegetativo } \\
\text { (início da prima- } \\
\text { vera) }\end{array}$ & $\begin{array}{c}\text { Final do florescimento } \\
\text { (final do verão) }\end{array}$ \\
\hline Altura (cm) & $42,4 \mathrm{~B}$ & $56,7 \mathrm{~A}$ \\
$\begin{array}{l}\text { Diâmetro (cm) } \\
\text { Parte aérea } \\
\text { (g MS/planta) }\end{array}$ & $21,2 \mathrm{~B}$ & $62,8 \mathrm{~A}$ \\
$\begin{array}{l}\text { Material morto } \\
\text { (g MS/planta) }\end{array}$ & Ausência & $43,5 \mathrm{~A}$ \\
\hline
\end{tabular}

Médias seguidas de mesma letra na linha não diferem pelo teste de Tukey $(\mathrm{P}>0,05)$.

A principal diferença foi verificada no diâmetro, que no estádio de florescimento foi $196 \%$ superior à verificada nas plantas em estádio vegetativo. Esse comportamento é natural, uma vez que, com o avanço do crescimento as plantas perenes cespitosas formam maior número de caules, mais área fotossintetizante e, conseqüentemente, maior quantidade de MS. Castro et al. (1999) observaram que Baccharis myriocephala teve um aumento linear na área foliar, altura e número de ramos em função dos dias de crescimento após o transplante das plantas, do campo para os vasos. Em seu trabalho, as plantas cortadas no início da primavera não apresentavam material morto, assim como o verificado neste estudo (Tabela 1), o que indicou a elevada tolerância da carqueja ao frio e às geadas.

$\mathrm{Na}$ avaliação da rebrota das plantas, os resultados evidenciaram efeito de estádio fenológico e altura de corte sobre alguns atributos morfofisiológicos, sem haver interação entre os fatores (Tabela 2). Na média das alturas de corte, as plantas cortadas no estádio vegetativo mostraram maior altura e produção de MS de hastes axilares, com menor acúmulo de material morto. Esse comportamento foi atribuído às temperaturas $\mathrm{e}$ precipitação pluviométrica favoráveis ao crescimento (Figura 1).

TABELA 2: Efeito de cortes em diferentes estádios fenológicos e alturas de corte na rebrota da carqueja.

\begin{tabular}{|c|c|c|c|c|}
\hline \multirow{2}{*}{ Caractere } & \multicolumn{2}{|c|}{$\begin{array}{c}\text { Estádio fenológico de } \\
\text { corte }\end{array}$} & \multicolumn{2}{|c|}{ Altura de corte } \\
\hline & Vegetativo & $\begin{array}{l}\text { Floresci- } \\
\text { mento }\end{array}$ & $7 \mathrm{~cm}$ & $15 \mathrm{~cm}$ \\
\hline Altura $(\mathrm{cm})$ & $36,7 \mathrm{~A}$ & $17,0 \mathrm{~B}$ & $22,0 \mathrm{~B}$ & $31,8 \mathrm{~A}$ \\
\hline Diâmetro (cm) & $43,0 \mathrm{~B}$ & $59,1 \mathrm{~A}$ & $48,3 \mathrm{~A}$ & $53,7 \mathrm{~A}$ \\
\hline $\begin{array}{l}\text { Hastes totais }\left(\mathrm{n}^{\circ} /\right. \\
\text { planta) }\end{array}$ & $44,6 \mathrm{~A}$ & $52,3 \mathrm{~A}$ & $45,7 \mathrm{~A}$ & $51,2 \mathrm{~A}$ \\
\hline $\begin{array}{l}\text { Hastes axilares } \\
\text { (g MS/planta) }\end{array}$ & $19,3 \mathrm{~A}$ & $7,4 \mathrm{~B}$ & $8,7 \mathrm{~B}$ & $18,0 \mathrm{~A}$ \\
\hline $\begin{array}{l}\text { Hastes axilares: } \\
\text { basilares } \\
\text { (g MS: g MS) }\end{array}$ & $6,5 \mathrm{~A}$ & $0,2 \mathrm{~B}$ & $3,0 \mathrm{~A}$ & $3,6 \mathrm{~A}$ \\
\hline $\begin{array}{l}\text { Material morto } \\
\text { (g MS/planta) }\end{array}$ & $2,0 \mathrm{~B}$ & $13,6 \mathrm{~A}$ & $7,7 \mathrm{~A}$ & 7,9 A \\
\hline
\end{tabular}

Apesar do diâmetro das plantas ter sido superior nas plantas cortadas no estádio de florescimento, a diferença com as plantas cortadas no estádio vegetativo não pode ser considerada efeito do tratamento, pois isso já havia sido verificado por ocasião da imposição 
dos tratamentos de corte (Tabela 1). No entanto, se considerada a diferença entre a imposição dos cortes e a avaliação da rebrota, o diâmetro teve aumento de 102\% nas plantas cortadas no estádio vegetativo, ao passo que aquelas cortadas no florescimento, o diâmetro não foi alterado (Tabela 2). A carqueja cresce ativamente na primavera, já que é uma planta estival (Rios et al., 2000), e, pelos dados obtidos neste estudo, seu crescimento se dá preferencialmente pela formação de hastes axilares, indicando que na primavera, a formação e o alongamento das hastes axilares foram preponderantes em relação à rebrota ocorrida durante o outono, o que pode ser observado na relação entre as hastes axilares e as hastes basilares (Tabela 2).

$\mathrm{Na}$ média dos estádios fenológicos, a altura de corte afetou a altura e a produção de MS das hastes superiores (Tabela 2). Plantas cortadas a $7 \mathrm{~cm}$ rebrotaram com menor vigor, indicando que a altura da roçada é um detalhe importante a ser considerado, quando o objetivo é reduzir o vigor da carqueja em áreas de pastagens. Porém, a rebrota das plantas, estimada pela produção de MS das hastes da coroa e do total da parte aérea (hastes basilares + hastes axilares), foi afetada pela interação estádio fenológico x altura de corte (Tabela 3).

TABELA 3: Efeito interativo de altura e estádio fenológico de corte na produção de matéria seca de hastes da coroa e no total da matéria seca verde da parte aérea de carqueja.

\begin{tabular}{cc}
\hline \multirow{2}{*}{$\begin{array}{c}\text { Estádio fenológico } \\
\text { de corte }\end{array}$} & \multicolumn{2}{c}{ Altura de corte } \\
\cline { 2 - 2 } & $7 \mathrm{~cm}$ \\
\hline
\end{tabular}

\begin{tabular}{lll}
\hline A) Parte aérea & & \\
Vegetativo & $16,4 \mathrm{aA}$ & $29,5 \mathrm{bA}$ \\
Florescimento & $21,7 \mathrm{aB}$ & $75,6 \mathrm{aA}$ \\
\hline
\end{tabular}

B) Hastes da coroa

Vegetativo $\quad 3,1 \mathrm{bA} \quad 4,2 \mathrm{bA}$

Florescimento $\quad 17,6 \mathrm{aB} \quad 64,9 \mathrm{aA}$

Médias seguidas de mesma letra minúscula na coluna e maiúscula na linha não diferem pelo teste de Tukey $(\mathrm{P}>0,05)$.

Plantas cortadas no estádio vegetativo mostraram resposta similar $(\mathrm{P}>0,05)$ sob cortes a 7 e a $15 \mathrm{~cm}$, tanto para a produção de hastes da coroa, quanto para o total produzido na parte aérea. Em compensação, o efeito da altura de corte foi distinto para as plantas cortadas no florescimento, havendo expressiva redução $(71 \%$ na parte aérea; $72 \%$ nas hastes da coroa) na capacidade de rebrota da carqueja sob corte a $7 \mathrm{~cm}$. Em plantas eretas, como a carqueja, cortes baixos eliminam grande parte das gemas axilares. Pellegrini et al. (2007), estudando o controle de carqueja em pastagem natural, observaram que as roçadas a $10-15 \mathrm{~cm}$ eliminaram a parte aérea das plantas, mas mantiveram parte das gemas axilares e todas as gemas basais, o que possibilitou o rebrota. Quando é deixada uma maior área residual há maior preservação das gemas, que são responsáveis pela rebrota na parte superior do dossel (Smith, 1962).

Comparando-se a produção total da parte aérea verificada entre os cortes realizados nos dois estádios fenológicos, apenas sob corte alto $(15 \mathrm{~cm})$ houve diferença entre as rebrotas, o que mostra que, sob cortes baixos, é indiferente roçar a carqueja no estádio vegetativo (início da primavera) ou no final do florescimento (final do verão). Esses resultados mostram, portanto, que, quanto à intensidade da roçada, há maior flexibilidade no período primaveril; já, no final do verão ou início do outono, quando as plantas estão em final de florescimento-frutificação, as roçadas devem ser mais intensas, pois ocorre expressiva formação de hastes basilares, reduzindo também a ressemeadura natural.

Nuñez e Del Puerto (1988), no Uruguai, destacaram que a carqueja possui dois períodos de brotação, um no outono e outro na primavera, sendo que a brotação de outono se faz basicamente a partir de brotos basilares, como foi constatado no presente trabalho (Figura 2). A matéria seca oriunda dessas hastes, após o corte no florescimento, foi reduzida drasticamente pelo corte mais intenso (Tabela 3). As plantas cortadas nessa época apresentaram maior MS dessas hastes, o que, na prática, torna o controle da espécie mais difícil. Segundo Smith (1962), plantas cortadas no florescimento rebrotam com mais vigor, em virtude de possuírem maior quantidade de fotoassimilados de reserva, o que impõe a necessidade de cortes mais drásticos para retardar seu crescimento.

Para efeito de manejo, os resultados mostraram que as plantas cortadas na primavera, quando estão em estádio vegetativo, apresentam menor produção de hastes basilares. Já, na rebrota de outono, essas hastes são os principais componentes da matéria seca aérea e gemas, 
por ficaram abaixo da altura de corte, proporcionam rebrotas vigorosas, o que implica em corte mais intenso, a fim de reduzir os pontos de crescimento das plantas.

Se o controle mecânico for feito na primavera, a altura da roçada pode ser maior, minimizando o dano às espécies desejáveis das pastagens naturais. Além disso, considerando-se que as pastagens naturais do sul do Brasil têm seu pico de crescimento na primaveraverão, pode-se esperar ainda uma melhor condição de concorrência das forrageiras nativas após as roçadas. Segundo Rios et al. (2000), também é preferível aplicar herbicidas para o controle da carqueja nessa estação, pois as plantas encontram-se em crescimento ativo e com baixo nível de reservas. O controle nessa fase fisiológica deprimiria substancialmente a translocação de fotoassimilados até os órgãos de reserva. Fontoura Jr. et al. (2007), em estudo de controle de plantas indesejáveis e ganho de peso animal em pastagem natural do Rio Grande do Sul, confirmaram a vantagem em praticar as roçadas na primavera, situação em que foi obtido maior ganho animal.

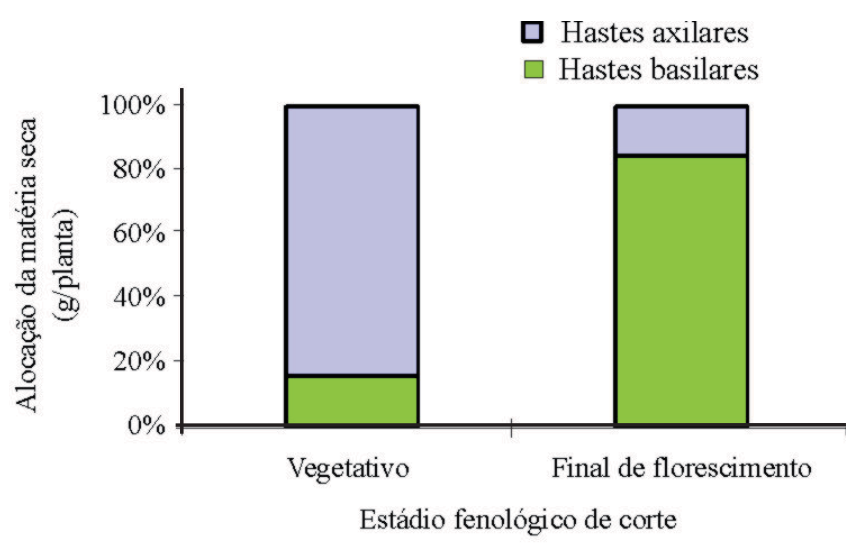

FIGURA 2: Alocação da matéria seca de plantas de carqueja na rebrota ocorrida após cortes realizados no estádio vegetativo e final de florescimento.

Nossas observações no campo indicaram a brotação das plantas a partir do sistema subterrâneo horizontal. A análise anatômica, realizada com a finalidade de esclarecer se sua estrutura era caulinar ou radicular, evidenciou tratar-se de raízesgemíferas (Figura 3), o que já havia sido citado por Nuñez e Del Puerto (1988), porém sem a comprovação anatômica.

A raiz é do tipo tetrarca, exibindo células corticais com pequenos espaços intercelulares e dispostas em cinco estratos celulares. A epiderme, a endoderme e o periciclo apresentam-se com uma única camada de células e o cilindro vascular é sólido, provido de quatro arcos. Segundo Appezzato-da-Glória (2003), tais características são típicas de estruturas radiculares. Essa autora destaca que raízes gemíferas são importantes para a recuperação de áreas que sofrem algum tipo de distúrbio, como queimadas. As raízes gemíferas apresentam uma porção central desprovida de medula verdadeira e presença de xilema primário com maturação centrípeta, tal como foi constatado neste estudo. Essas raízes são meios de propagação vegetativa da espécie, o que possibilita a formação de novos indivíduos próximos à planta-mãe, podendo resultar num padrão de distribuição espacial agregada, o que é encontrado na carqueja presente em meio às pastagens naturais.

A confirmação da ocorrência de raízes gemíferas em carqueja evidencia, portanto, a importância dos cuidados a serem tomados quanto ao seu controle, pois essa estrutura, se fragmentada por máquinas agrícolas, é capaz de gerar novas plantas a partir da ativação de gemas dormentes ou de novas gemas vegetativas, tal como ocorre com rizomas (Llaana et al., 2004).

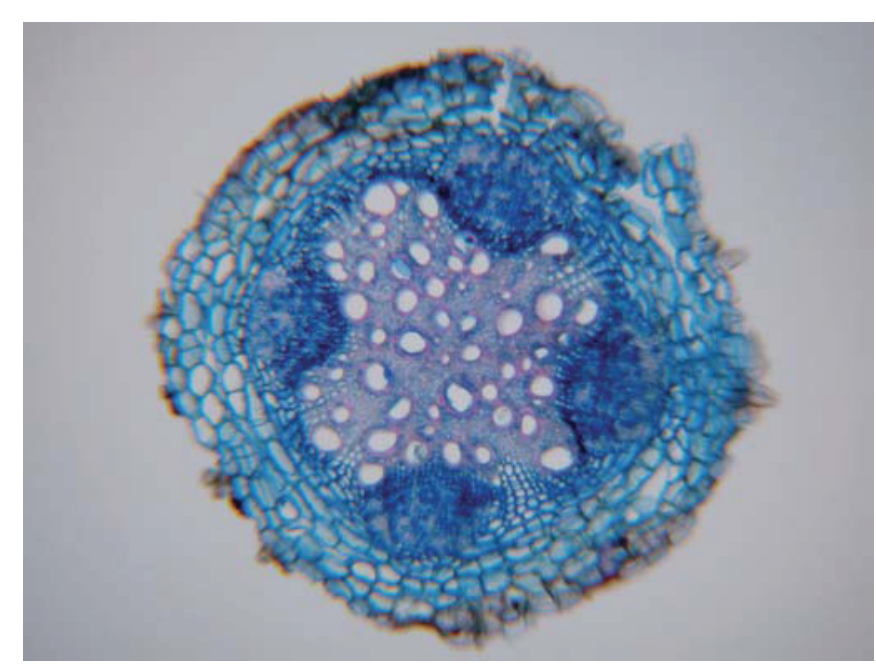

FIGURA 3: Corte transversal de raiz de Baccharis trimera em estrutura primária, localizada paralelamente à superfície do solo. Córtex (c); floema (f); xilema (x). Barra $=50 \mu \mathrm{m}$.

Considerando os resultados obtidos, pode-se inferir que o controle da carqueja em pastagens naturais é mais eficaz quando as roçadas ocorrem no início da 
primavera, época em que as plantas estão em estádio vegetativo, podendo ser a maior altura, o que seria menos danoso às plantas desejáveis. Se essa prática ocorrer no final do outono, quando as plantas estão no final do florescimento, o corte deve ser a menor altura $(7 \mathrm{~cm})$, deixando-se o menor resíduo possível, a fim de eliminar e/ou inibir o crescimento das hastes basilares, oriundas da coroa e/ou das raízes gemíferas.

\section{Referências}

Appezzato-da-Glória, B. 2003. Morfologia de sistemas subterrâneos: História e evolução do conhecimento no Brasil. Editora e Arte, Ribeirão Preto, Brasil, 80pp.

Biasi, L. A.; De Bona, C. M. 2000. Propagação de carqueja (Baccharis trimera (Less) DC.) por meio de estaquia. Revista Brasileira de Plantas Medicinais, 2: 37-43.

Castro, H. G.; Ferreira, F. A. 2000. Contribuição ao estudo das plantas medicinais: carqueja (Baccharis genistelloides). Editora UFV, Viçosa, Brasil, 102pp.

Castro, H. G.; Casali, V. W. D.; Cecon, P. R. 1999. Crescimento inicial e épocas de colheita em seis acessos de Baccharis myriocephala DC. Revista Brasileira de Plantas Medicinais, 2: 1-6.
Fontoura Jr., J. A. de.; Carvalho, P. C. de F.; Nabinger, C.; Silva, J. J. S. da.; Pinto, C. E.; Crancio, L. A. 2007. Produção animal em pastagem submetida ao controle de plantas indesejáveis e a intensidades de pastejo. Ciência Rural, 37: 247-252.

Llana, V. H.; Llana, M. del C.; Billard, C.; Elizalde, J. H. I. 2004. Brotación de rizomas de Eryngium horridum Malme (Apiaceae) durante un ciclo anual. Revista de la Facultad de Agronomia, 105: 1-10.

Nuñez, H.; Del Puerto, O. 1988. Biologia de Baccharis trimera (carqueja). Memorias de la Reunion del Grupo Tecnico Regional del Cono Sur en Mejoramiento y Utilización de los Recursos Forrageros del Area Tropical y Subtropical, Tacuarembó, Uruguay, p.99-102.

Pellegrini, L. G. de.; Nabinger, C.; Carvalho, P. C. de F.; Neumann, M. 2007. Diferentes métodos de controle de plantas indesejáveis em pastagem nativa. Revista Brasileira de Zootecnia, 36: 12471254.

Rios, A.; Ibarra, M.; Roth, Y. 2000. Siembras sin laboreo em campos sucios. I. Control de campo sucio y producción de verdeos. Disponível em <http: www.inia.org.uy/publicaciones/documentos/ le/ad>. Acesso em 23 de maio de 2008.

Romo, J. T.; Eddlemann, L. E. 1995. Use of degree-days in multiple-temperature experiments. Journal of Range Management, 48: 410-416.

Smith, D. 1962. Carbohydrates root reserves in alfalfa, red clover and birdsfoot trefoil under management schedules. Crop Science, 2: $75-78$. 